\title{
CONTROLE DO AMADURECIMENTO DE CARAMBOLAS COM 1-MCP1
}

\author{
GUSTAVO HENRIQUE DE ALMEIDA TEIXEIRA² E JOSÉ FERNANDO DURIGAN ${ }^{3}$
}

\begin{abstract}
RESUMO - O 1-metilciclopropeno (1-MCP) inibe a ação do etileno retardando o amadurecimento de muitos frutos climatéricos e não-climatéricos. Considerando a potencialidade do 1-MCP em retardar o amadurecimento, o objetivo deste trabalho foi avaliar o efeito inibitório desse bloqueador da ação do etileno sobre o amadurecimento de carambolas mantidas em condições de ambiente. Frutos da cultivar Fwang Tung,

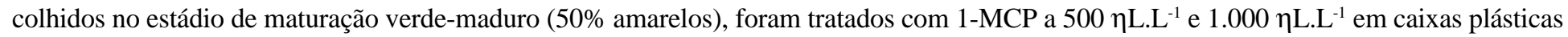
hermeticamente fechadas por 24 horas, a $25^{\circ} \mathrm{C}$. Depois da aplicação, estes frutos e os controle (sem tratamento) foram transferidos para ambiente a $21,6^{ \pm} 0,9^{\circ} \mathrm{C}$ e $59,7 \%$ UR, onde foram mantidos por até nove dias, sendo amostrados a cada três dias. O delineamento utilizado foi o inteiramente casualizado, em esquema fatorial (duas concentrações de 1-MCP e o controle, com quatro períodos de avaliação). Foram utilizadas três repetições com seis frutos por tratamento e período de avaliação. A respiração dos frutos foi significativamente reduzida em 36,62\% e

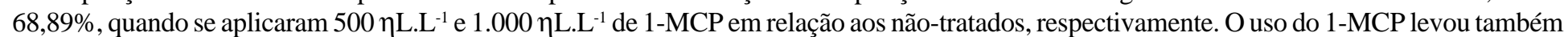
à melhor manutenção da coloração dos frutos, todavia o amadurecimento dos mesmos não foi significativamente retardado pelo uso deste produto.
\end{abstract}

Termos para indexação: Averrhoa carambola L., respiração, coloração, 1-metilciclopropeno.

\section{RIPENING CONTROL OF CARAMBOLAS WITH 1-MCP}

\begin{abstract}
MCP) inhibits ethylene action retarding ripening in various climacteric and non-climacteric fruits. Considering the 1-MCP potentialities in delaying ripening, the objective of this study was to evaluate the inhibitory effect of this ethylene blocker on ripening of carambola fruits kept in ambient condition. Fruits of Fwang Tung cultivar, harvested at mature green maturity stage (50\% yellow), were treated with 1-MCP at $500 \eta{\mathrm{L} . \mathrm{L}^{-1}}^{-1}$ and $1000 \eta \mathrm{L} . \mathrm{L}^{-1}$ in plastic boxes hermetically shut for 24 hours at $25^{\circ} \mathrm{C}$. After the application, these fruits and the control (without treatment) were transferred to an ambient at $21.6^{ \pm} 0.9^{\circ} \mathrm{C}$ and $59.7 \% \mathrm{RH}$, where they were maintained for up to nine days, and were sampled at each three days. The experiment was arranged as completely randomized design in a factorial scheme (two concentrations of 1-MCP and the control, with four periods of evaluation). It was used three replications of six fruits per treatment and periods of evaluation. Fruit respiration was significantly reduced in $36.62 \%$ and $68.89 \%$, when was applied $500 \eta L . L^{-1}$ and $1000 \eta L . L^{-1}$ of $1-M C P$ in relation to untreated fruits, respectively. The use of 1-MCP also led to a better fruit colour maintenance, however, ripening was not significantly delayed by the use of this product.
\end{abstract}

Index terms: Averrhoa carambola L., respiration, Fwang Tung, 1- methylcyclopropene.

\section{INTRODUÇÃO}

A caramboleira (Averrhoa carambola L.) é uma fruteira tropical que atualmente está distribuída por todo o mundo, podendo ser encontrada na Austrália, Filipinas e outras ilhas do Pacífico Sul, América Central e do Sul, Caribe, África, Israel e em áreas subtropicais dos Estados Unidos (LENNOX \& RAGOONATH, 1990).

A carambola é considerada uma fruta climatérica por VINES \& GRIERSON (1966) e SHIESH et al. (1987), enquanto outros pesquisadores (OSLUND \& DAVENPORT, 1983; LAM \& WAN, 1987; MITCHAN \& McDONALD, 1991) não encontraram o pico respiratório e a consideraram não-climatérica. LAM \& WAN (1987) relataram que a carambola carece de resposta ao etileno autocatalítico, comumente observada em frutos climatéricos. Embora se tenha que a produção de etileno endógeno foi estimulada durante a exposição ao etileno, observou-se também decréscimo, logo após a remoção do tratamento com este produto.

Segundo O'HARE (1995), elevações apreciáveis na respiração e na produção de etileno ocorrem quando as carambolas são expostas a elevadas temperaturas de armazenamento, dessecação e doenças, o que leva ao rápido amadurecimento dos frutos.

De acordo com WILLS et al. (1998), o amadurecimento pode ser atrasado por meio do uso de inibidores da ação do etileno, entre os quais se destaca o 1-metilciclopropeno (1-MCP). Para SISLER \& SEREK (1997), a ação do etileno é inibida quando o 1-MCP se liga aos receptores deste fitorregulador nos vegetais. Todavia, ainda não se sabe como o 1-MCP se liga aos receptores de etileno e por que ele pode ligar-se a estes locais (PRANGE \& DeLONG, 2003). BINDER \&
BLEECKER (2003) sugeriram que ele se liga ao cobre, co-fator do receptor de etileno, mas talvez devido a um obstáculo esteárico, a ligação é insuficiente para converter os receptores para o estado inativo.

Vários estudos têm verificado que o 1-MCP, além de restringir a ação do etileno, pode reduzir sua produção e retardar o amadurecimento de muitos frutos climatéricos, como a banana (SISLER \& SEREK, 1997), o pêssego (KLUGE \& JACOMINO, 2002) e de nãoclimatéricos (SISLER \& SEREK, 1997).

Considerando a potencialidade do 1-MCP em retardar o amadurecimento de frutos, o objetivo do presente trabalho foi avaliar o efeito inibitório desse bloqueador da ação do etileno sobre o amadurecimento de carambolas.

\section{MATERIAL E MÉTODOS}

Material vegetal e aplicação dos tratamentos: Foram utilizados frutos da cultivar Fwang Tung, provenientes do pomar da Estação Experimental de Citricultura de Bebedouro, no estádio de maturação verde-maduro, ou seja, com metade de sua coloração amarela.

Após o recebimento no Laboratório de Tecnologia dos Produtos Agrícolas da FCAV / UNESP, Câmpus de Jaboticabal, os frutos foram selecionados, lavados com detergente neutro, enxaguados em água corrente e imersos em solução de hipoclorito de sódio a $200 \mathrm{mg} . \mathrm{L}^{-1}$, por 5 minutos. Depois de secos, foram submetidos aos seguintes tratamentos: aplicação de 1metilciclopropeno (1-MCP) a $500 \eta L^{-L^{-1}}$; 1-MCP a $1.000 \eta L . L^{-1} \mathrm{e}$

\footnotetext{
${ }^{1}$ (Trabalho 07-2006). Recebido: 11-01-2006. Aceito para publicação: 21-09-2006. FAPESP (Proc. 00/13237-9) e CAPES (BEX 0391/02-6).

2 Pós-doutorando da UNESP, Faculdade de Ciências Agrárias e Veterinárias, Depto. Tecnologia, Via de acesso Prof. Paulo Donato Castellane s/n, Jaboticabal - SP, CEP 14.887-900, Telefone 16 3209-2675, Fax 16 3202-4275, E-mail teixeiragha@ yahoo.com.br *FAPESP (Proc. 00/13237-9) e CAPES (BEX 0391/ 02-6).

${ }^{3}$ Professor Titular da UNESP, Faculdade de Ciências Agrárias e Veterinárias, Depto. Tecnologia, Via de acesso Prof. Paulo Donato Castellane s/n, Jaboticabal - SP, CEP 14.887-900, Telefone 16 3209-2675, Fax 16 3202-4275, E-mail jfduri@fcav.unesp.br
} 
controle (sem aplicação do 1-MCP). Para estas aplicações, foram utilizadas caixas plásticas de $0,186 \mathrm{~m}^{3}$ com fechamento hermético, por 24 horas, a $25^{\circ} \mathrm{C}$. As doses desejadas de 1-MCP foram conseguidas pesando-se $0,149 \mathrm{~g}$ e $0,298 \mathrm{~g}$ do produto comercial Ethylbloc $^{\mathrm{TM}}, 0,14 \%$ ia (Rohm and Hass Química Ltda., São Paulo, Brasil), para as concentrações de 500 e $1.000 \eta L^{2} L^{-1}$, respectivamente. Após a pesagem, em recipiente de vidro, ao produto foi adicionado $20 \mathrm{~mL}$ de água deionizada a $50^{\circ} \mathrm{C}$, e estes recipientes imediatamente abertos no interior das caixas plásticas.

Depois da aplicação do 1-MCP, os frutos foram mantidos sob condições de ambiente $\left(21,6^{ \pm} 0,9^{\circ} \mathrm{C} ; 59,7 \%\right.$ UR) por até nove dias, sendo amostrados a cada três dias, ou seja, aos 0; 3; 6 e 9 dias, com a determinação dos seguintes parâmetros:

Perda de massa fresca: Durante o armazenamento, esta foi calculada através da pesagem dos frutos em balança eletrônica (Marte, modelo AS 2000, São Paulo, Brasil) com precisão de 0,01 grama.

Coloração: Foi determinada utilizando-se do sistema CIE L*a*b, reflectômetro Minolta (Modelo CR-200b, Minolta, Osaka, Japão), com o qual se realizaram duas leituras por fruto nas "costelas" (região carpelar), nos seis frutos de cada repetição, e ela foi expressa em luminosidade (L), ângulo hue ou de cor $\left({ }^{\circ} h\right)$ e cromaticidade, conforme o descrito por MILLER \& McDONALD (1991).

Atividade respiratória: Foi mensurada utilizando-se de um cromatógrafo a gás (Finningan, modelo 9001, Finningan Corporation, San Jose, EUA), através da determinação da quantidade de gás carbônico $\left(\mathrm{CO}_{2}\right)$ liberado pelos frutos. Esta análise foi feita em triplicata para cada tratamento, cujos frutos foram mantidos por uma hora em recipiente hermeticamente fechado (baldes plásticos de 3,2 L), determinando-se o teor de $\mathrm{CO}_{2}$ na atmosfera ambiente, antes e depois deste período. Uma amostra de $0,3 \mathrm{~mL}$ foi injetada no cromatógrafo que estava equipado com colunas de aço inox de $3 \mathrm{~m}$ de comprimento por $4 \mathrm{~mm}$ de diâmetro contendo Porapack-N e peneira molecular (5A), detector de condutividade térmica $\left(150^{\circ} \mathrm{C}\right)$, e detector de ionização de chama $\left(150^{\circ} \mathrm{C}\right)$, usando nitrogênio como gás de arraste $(30 \mathrm{~mL}$ $\left.\min ^{-1}\right)$. Esta determinação tornou possível calcular a atividade respiratória e expressá-la em $\mathrm{mg}$ de $\mathrm{CO}_{2} \mathrm{~kg}^{-1} \mathrm{~h}^{-1}$. A atividade respiratória foi determinada nos dias $0 ; 3 ; 6$ e 9 .

Análises físico-químicas: Os frutos foram homogeneizados, congelados e armazenados a $-10^{\circ} \mathrm{C}$, sendo posteriormente utilizados para a determinação dos teores de sólidos solúveis (SS) e acidez titulável (AT), segundo os métodos preconizados pela A.O.A.C. (1997), além do pH e da relação SS/AT.

Análise estatística. $\mathrm{O}$ experimento foi conduzido segundo um delineamento inteiramente casualizado, em esquema fatorial 3 (duas doses de 1-MCP e o controle) x 4 (quatro períodos de avaliação), com três repetições. A unidade experimental foi composta por um grupo de seis frutos, e os dados obtidos foram analisados

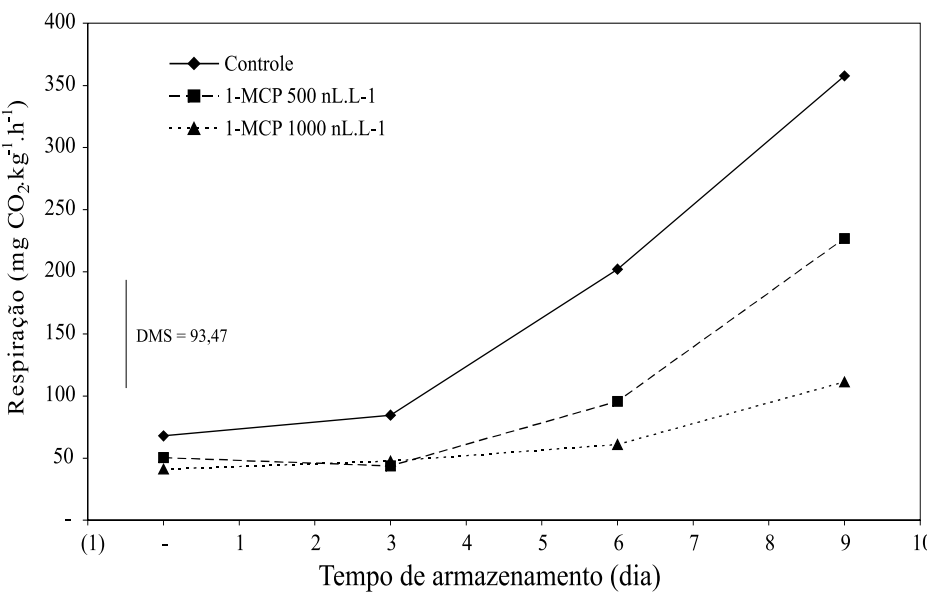

FIGURA 1 - Taxa respiratória $\left(\mathrm{mg}\right.$ de $\left.\mathrm{CO}_{2} \cdot \mathrm{kg}^{-1} \cdot \mathrm{h}^{-1}\right)$ de carambolas 'Fwang Tung', submetidas a diferentes tratamentos, e armazenadas sob condições de ambiente $\left(21,6^{ \pm} 0,9^{\circ} \mathrm{C}\right.$; $59,7 \%$ UR). estatisticamente através do programa SAS (1996).

\section{RESULTADOS E DISCUSSÃO}

A respiração dos frutos foi significativamente afetada pela aplicação do 1-MCP (Figura 1). A taxa respiratória que inicialmente era de 47,93 mg de $\mathrm{CO}_{2} \mathrm{~kg}^{-1} \mathrm{~h}^{-1}$ aumentou de maneira mais acentuada nos frutos que não sofreram tratamento algum e atingiu $357,67 \mathrm{mg}$ de $\mathrm{CO}_{2} \mathrm{~kg}^{-1} \mathrm{~h}^{-1}$ no 9o dia de armazenamento. Esta taxa foi reduzida em $36,62 \%$ e 68,89\% quando se aplicaram $500 \eta L_{L} L^{-1}$ e 1.000 ๆL.L ${ }^{-1}$ de 1MCP, respectivamente. Reduções semelhantes (60\%) também foram observadas por KLUGE et al. (2000) em goiabas 'Pedro Sato' tratadas com 240 ppb de 1-MCP.

Embora a aplicação do 1-MCP tenha reduzido a taxa respiratória, esta aumentou durante o armazenamento a partir do $6^{\circ}$ dia (Figura 1). O'HARE (1995) também observou incrementos respiratórios em carambolas armazenadas a $15^{\circ} \mathrm{C}$ e $25^{\circ} \mathrm{C}$. Este autor relacionou o aumento da produção de $\mathrm{CO}_{2}$ à presença de podridões que também promoveram incremento nos teores de etileno. LAM \& WAN (1987) e MITCHAN \& McDONALD (1991) também relataram que a produção de etileno em carambolas é geralmente baixa, aumentando gradualmente com o tempo, devido à presença de patógenos.

A presença de podridões foi observada somente no 9 dia de armazenamento e foi particularmente menor nos frutos tratados

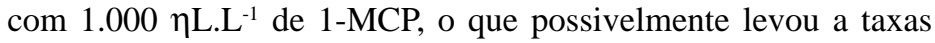
respiratórias mais reduzidas. O uso do 1-MCP nas doses de $120 \mathrm{ppb}$ e $240 \mathrm{ppb}$ também resultaram em menor porcentagem de podridões e menor taxa respiratória em goiabas 'Pedro Sato' (KLUGE et al., 2000).

Qualquer que seja o caso, sem a ação do etileno, uma série de processos biológicos, além da respiração são minimizados por um período variável segundo a espécie vegetal, como, por exemplo, a degradação da clorofila e conseqüente mudança de coloração (WILLS et al., 1998).

A coloração das carambolas foi significativamente afetada pela aplicação do 1-MCP, principalmente o ângulo hue (Figura 2). Este ângulo $\left({ }^{\circ} h\right)$ diminuiu mais rapidamente nos frutos que não foram tratados com 1-MCP, principalmente após o 3 - dia de armazenamento (Figura 2). Os demais tratamentos mantiveram a coloração das costelas mais verdes, o que resultou em valores maiores, ${ }^{0} h=110,08 \mathrm{e}$ ${ }^{0} h=108,00$ nos frutos tratados com 500 e 1.000 ๆL.L.1 de 1-MCP, respectivamente.

A aplicação do 1-MCP também resultou em frutos com

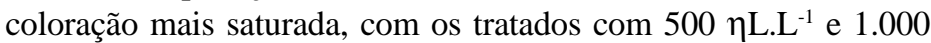
$\eta L . L^{-1}$, mostrando maior cromaticidade (Tabela 1). Entretanto os valores de cromaticidade permanecem constantes durante o amadurecimento. A luminosidade foi o único parâmetro da coloração

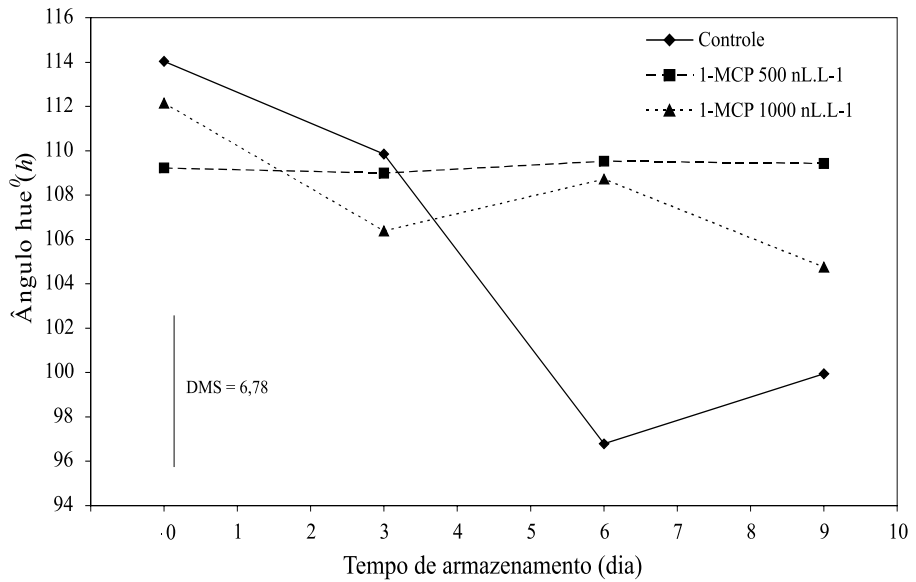

FIGURA 2. Ângulo hue $\left({ }^{\circ} h\right)$ de carambolas 'Fwang Tung', submetidas a diferentes tratamentos, e armazenadas sob condições de ambiente $\left(21,6^{ \pm} 0,9^{\circ} \mathrm{C} ; 59,7 \%\right.$ UR) 
TABELA 1 - Luminosidade e cromaticidade de carambolas 'Fwang Tung', submetidas a diferentes tratamentos, e armazenadas sob condições de ambiente $\left(21,6^{ \pm} 0,9^{\circ} \mathrm{C} ; 59,7 \%\right.$ UR).

\begin{tabular}{lcc}
\hline Efeitos principais & Luminosidade & Cromaticidade \\
\hline Tratamentos (Trat) & & \\
Controle & 55,17 & $17,62 \mathrm{~b}$ \\
$1-\mathrm{MCP} 500 \eta L . \mathrm{L}^{-1}$ & 52,70 & $21,76 \mathrm{a}$ \\
$1-\mathrm{MCP} 1000 \eta \mathrm{L}^{-1}$ & 54,19 & $19,11 \mathrm{ab}$ \\
Tempo de armazenamento (T) & & \\
0 & 52,69 & 20,88 \\
3 & 55,34 & 19,37 \\
6 & 55,36 & 20,04 \\
9 & 52,69 & 17,76 \\
Interação & & \\
Trat x T & $\mathrm{NS}$ & $\mathrm{NS}$ \\
C.V. $(\%)$ & 4,86 & 18,46 \\
\hline Médias seguidas de, pelo menos, uma mesma letra, nas colunas, não diferem estatisticamente entre si, pelo teste de Tukey (P<0,05). NS, não-significativo.
\end{tabular}

TABELA 2 - Parâmetros físicos e físico-químicos de carambolas 'Fwang Tung', submetidas a diferentes tratamentos, e armazenadas sob condições de ambiente $\left(21,6^{ \pm} 0,9^{\circ} \mathrm{C} ; 59,7 \% \mathrm{UR}\right)$.

\begin{tabular}{|c|c|c|c|c|c|}
\hline Efeitos principais & $\begin{array}{c}\text { SS } \\
\left({ }^{0} \text { Brix }\right) \\
\end{array}$ & $\begin{array}{c}\mathbf{A \mathbf { T } ^ { \mathbf { 1 } }} \\
\left(\mathrm{mg} 100 \mathrm{~g}^{-1}\right)\end{array}$ & SS/AT & pH & $\begin{array}{c}\text { PMF }^{2} \\
(\%)\end{array}$ \\
\hline \multicolumn{6}{|l|}{ Tratamentos (Trat) } \\
\hline Controle & 7,73 & 0,36 & 24,98 & 3,91 & $3,18 \mathrm{ab}$ \\
\hline 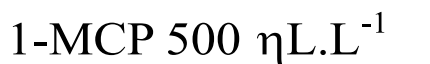 & 7,92 & 0,36 & 26,85 & 3,99 & 5,18 a \\
\hline 1-MCP $1000 \eta L^{-L^{-1}}$ & 8,22 & 0,35 & 27,96 & 3,96 & $2,74 \mathrm{~b}$ \\
\hline \multicolumn{6}{|c|}{ Tempo de armazenamento (T) } \\
\hline 0 & 7,70 & $0,62 \mathrm{a}$ & $12,61 \mathrm{~b}$ & $3,72 \mathrm{~b}$ & $0,00 \mathrm{~b}$ \\
\hline 3 & 7,84 & $0,27 \mathrm{~b}$ & $30,18 \mathrm{a}$ & $4,02 \mathrm{a}$ & $1,61 \mathrm{~b}$ \\
\hline 6 & 7,82 & $0,27 \mathrm{~b}$ & $30,64 \mathrm{a}$ & $4,04 \mathrm{a}$ & $5,34 \mathrm{a}$ \\
\hline 9 & 8,47 & $0,26 \mathrm{~b}$ & $32,96 \mathrm{a}$ & $4,03 \mathrm{a}$ & $7,85 \mathrm{a}$ \\
\hline \multicolumn{6}{|l|}{ Interação } \\
\hline Trat $\mathrm{x} T$ & NS & NS & NS & NS & NS \\
\hline C.V. $(\%)$ & 10,11 & 16,56 & 23,34 & 3,28 & 55,46 \\
\hline
\end{tabular}

- ${ }^{1}$ acidez titulável em gramas de ácido cítrico por $100 \mathrm{~g}^{-1}$ de polpa fresca; ${ }^{2}$ perda de massa fresca (\%). - Médias seguidas de, pelo menos, uma mesma letra, nas colunas, não diferem estatisticamente entre si, pelo teste de Tukey $(\mathrm{P}<0,05)$. NS, não-significativo.

que não foi afetado pela aplicação do 1-MCP (Tabela 1) e também não apresentou qualquer modificação ao longo do armazenamento, permanecendo praticamente constante em $\mathrm{L}=54,02 \pm 2,92$.

Apesar das diferenças na atividade metabólica e na coloração, a aplicação do 1-MCP não retardou o amadurecimento dos frutos, pois não se observaram mudanças significativas entre os tratamentos quanto aos parâmetros físico-químicos (Tabela 2).

Não se observaram mudanças significativas nos teores de sólidos solúveis (SS) durante todo o período de armazenamento (Tabela 2), cujo valor médio foi de 7,96 $0,78^{\circ}$ Brix, reafirmando o observado por CAMPBELL et al. (1989).

A acidez titulável (AT) diminuiu significativamente durante o armazenamento em todos os tratamentos (Tabela 2), coincidindo também com as mudanças do valor de $\mathrm{pH}$. Reduções na concentração da AT também foram relatadas por O'HARE (1995) e CAMPBELL et al. (1989). Estas observações diferem das apresentadas neste trabalho, embora é possível que estas diferenças estejam relacionadas com as cultivares utilizadas por estes autores, 'Maha', 'Arkin' e 'Golden Star', respectivamente.
A relação SS/AT refletiu no comportamento da AT, uma vez que não houve modificações nas concentrações de SS (Tabela 2). Segundo WILSON III (1990), a relação SS/AT ótima para o consumo da carambola é 12,6, menor que os valores observados neste trabalho, indicando que estes frutos são de qualidade superior àqueles.

A perda de massa fresca (PMF) foi influenciada pelo uso do 1-MCP e aumentou acentuadamente durante o armazenamento (Tabela 2). Este efeito refletiu a incidência de podridões que foi menor nos frutos tratados com $1.000 \eta$ L.L $L^{-1}$ de 1-MCP. A PMF chegou a $7,85 \%$ no 9 dia de armazenamento, mas não foi observado qualquer sintoma de desidratação. Todavia, PANTASTICO et al. (1979) relataram que perdas de $5,0 \%$ podem ser suficientes para promover murcha e enrugamento, afetando a qualidade de frutos e hortaliças.

\section{CONCLUSÕES}

O uso do 1-MCP reduziu a atividade respiratória de carambolas e levou a melhor manutenção da coloração dos frutos. Contudo, os parâmetros físico-químicos evoluíram normalmente, ou 
seja, o amadurecimento dos mesmos não foi significativamente retardado pelo uso deste produto.

\section{AGRADECIMENTOS}

A Fundação de Amparo à Pesquisa do Estado de São Paulo (FAPESP proc. 00/13237-9) e à Coordenadoria de Aperfeiçoamento do Pessoal de Ensino Superior (CAPES BEX 0391/02-6), pelas bolsas de estudo e apoio financeiro.

\section{REFERÊNCIAS}

A.O.A.C. Official methods of analysis of the Association of Official Analytical Chemists. 12 ${ }^{\text {th }}$ ed. Washington: A.O.A.C,. 1997. $1.115 p$.

BINDER, B.M.; BLEECKER, A.B. A model for ethylene receptor function and 1-methylcyclopropene action. Acta Horticulturae, Wageningen, n.682, p.177-87, 2003.

CAMPBELL, C.A.; HUBER, D.J.; KOCH, K.E. Postharvest changes in sugar, acids, and color of carambola fruit at various temperatures. HortScience, Alexandria, v.24, n.3, p.472-475, 1989.

KLUGE, R.A.; JACOMINO, A.P. Shelf life of peaches treated with 1methylcyclopropene, Scientia Agricola, Piracicaba, v.59, n.1, p.69-72, 2002.

KLUGE, R.A.; JACOMINO, A.P.; CASTRO, P.R.C. Controle do amadurecimento e senescência de goiaba vermelha tratada com Ethylblock (1-MCP). In: CONGRESSO BRASILEIRO DE FRUTICULTURA, 16., 2000, Fortaleza. Anais... Fortaleza: EMBRAPA, 2000. p.292. CD-ROM

LAM, P.F.; WAN, C.K. Ethylene and carbon dioxide production of star fruits (Averrhoa carambola L.) stored at various temperatures and in different gas and relative humidity atmospheres. Tropical Agriculture, St. Augustine, v.64, n.3, p.181-184, 1987.

LENNOX, A.; RAGOONATH, J. Carambola and bilimbi. Fruits, Paris, v.45, n.5, p.497-501, 1990.

MILLER, W.R.; McDONALD, R.E. Quality of 'Arkin' carambolas with or without conditioning followed by low-temperature quarantine treatment. Proceedings of the Florida State Horticultural Society, Winter Haven, n.104, p.118-122, 1991.
MITCHAM, E.J.; McDONALD, R.E. Characterization of the ripening of carambola (Averrhoa carambola L.). fruit. Proceedings of the Florida State Horticultural Society, Winter Haven, n.104, p.104$108,1991$.

O'HARE, T.J. The potential for mixed transport of selected tropical fruit. Hamilton: DPI, 1995. 100p.

OSLUND, C.R.; DAVENPORT, T.L. Ethylene and carbon dioxide in ripening fruit of Averrhoa carambola. HortScience, Alexandria, v.18, n.2, p.229-230, 1983.

PANTASTICO, Er.B.; CHATTOPADHYAY, T.K.; SUBRAMANYAM, $\mathrm{H}$. Almacenamiento y operaciones comerciales de almacenaje. In: PANTASTICO, Er.B. (Ed.). Fisiologia de la postrecoleccion manejo y utilizacion de frutas y hortalizas tropicales y subtropicales. Mexico: Compañia Editorial Continental, 1979. p.375-405.

PRANGE, R.K.; DeLONG, J.M. R. 1-methylcyclopropene: the "magic bullet" for horticultural products? Chronica Horticulturae, Wageningen, v.43, n.1, p.11-14, 2003.

SAS INSTITUTE. SAS User's guide: Statistics. $6^{\text {th }}$ ed. Cary, 1996. 956p.

SHIESH, C.C.; LIN, T.S.; TSAI, P.L. Respiration and ethylene production of harvested carambola fruits (Averrhoa carambola L.). Journal of Chinese Horticultural Science, v.33, p.139-150, 1987.

SISLER, E.C.; SEREK, M. Inhibitors of ethylene responses in plants at the receptor level: recent developments. Physiologia Plantarum, Copenhagen, v.100, n.1, p.577-582, 1997.

VINES, H.M.; GRIERSON, W. Handling and physiological studies with the carambola. Proceedings of the Florida State Horticultural Society, Winter Haven, v.79, p.350-354, 1966.

WILLS, R.; McGLASSON, B.; GRAHAM, D.; JOYCE, D. Postharvest: an introduction to the physiology \& handling of fruit, vegetables \& ornamentals. Sydney: UNSW Press, 1998. 262p.

WILSON III, C.W. Carambola and Bilimbi. In: NAGY, S.; SHAW, P.E.; WARDOWSKY, F.S. (Ed.). Fruits of tropical and subtropical origin: composition, properties and uses. Lake Alfred: Florida Science Source, 1990. p.277-301. 